\title{
Rainfall Thresholds for Homeland Security in Mountainous Townships of Taiwan during Typhoon Morakot
}

\author{
Chien-Yuan Chen and Jui-Tang Chiang, Member, IACSIT
}

\begin{abstract}
Global warming is causing rapid changes in weather patterns. Such changes have brought extreme rainfall in Taiwan and caused numerous hazards in recent years. Typhoon Morakot made landfall in Taiwan on 8 August 2009 and caused 677 deaths, with 22 missing. Its extreme rainfall was concentrated in the mountainous areas of southern Taiwan in Chiayi, Tainan, Kaohsiung, and Pingtung counties. The rainfall caused the most severe natural hazards in the southern mountainous areas of Taiwan in recent years. This study performs a statistical analysis of hazards and rainfall distribution in the mountainous areas of Chiayi County during Typhoon Morakot. The results of the analysis show that the number of hazards in the mountainous areas increased with the rainfall. As rainfall increased over a threshold value, the number of hazards also increased abruptly. The cumulative number of hazards and the time of rainfall duration showed a power-law distribution over a threshold rainfall. A novel rainfall threshold index, the $D I_{t}$ or Disaster Intensity in a time interval for torrential rainfall-induced hazards caused by typhoons is proposed herein to indicate the intensity of increasing hazards during Typhoon Morakot. The proposed index could be extended to future typhoons to aid in hazard warnings for homeland security. The threshold rainfall can be used as an index for hazard prevention and emergency response in the studied mountainous townships and other areas.
\end{abstract}

Index Terms - Typhoon morakot, rainfall threshold, hazard warning, GIS.

\section{INTRODUCTION}

Climate change induced extreme rainfall has caused numerous global disasters in recent years [1]-[3]. Typhoon Morakot made landfall in Taiwan on 8 August 2009, bringing heavy rainfall. The typhoon caused 677 deaths with a further 22 missing. It cut water supplies to 769,159 households, electric power to $1,595,419$ households, and communications to 22,221 households [4]. Water resources facilities and levees were damaged in 824 places, roads were blocked in 250 locations, 196 bridges were damaged, and the total flooded area reached $765 \mathrm{~km}^{2}$ [4]. The economic losses of agricultural and fisheries industries were estimated at NT\$ 192 billion [5]. The typhoon, combined with south-western winds, brought heavy rainfall concentrated in southern Taiwan (Fig. 1). The typhoon caused the most serious flood hazards in the recorded history of Taiwan.

Manuscript received March 9, 2014; revised May 22, 2014.

The authors are with the Civil and Water Resources Engineering, National Chiayi University, Chiayi City 60004, Taiwan (e-mail: chienyuc@mail.ncyu.edu.tw, kaitou173@yahoo.com.tw).

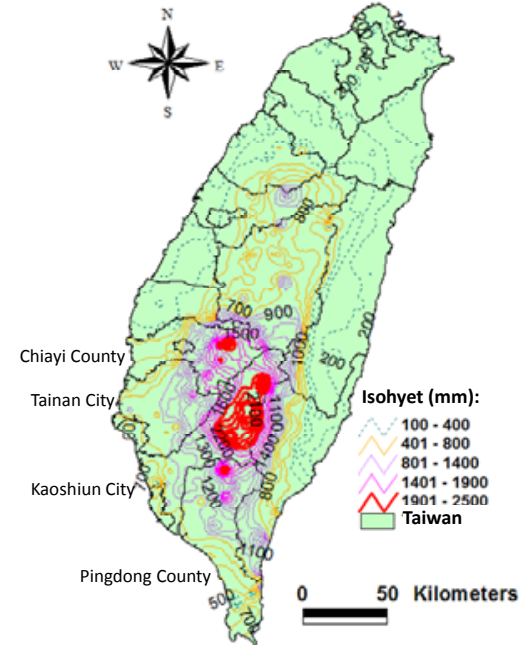

Fig. 1. Rainfall distribution during 7-10 august 2009 typhoon Morakot landed on Taiwan (source [6]).

The disaster areas induced by Typhoon Morakot were located in central and southern Taiwan. The main hazards included floods, debris flows, landslides, broken bridges, damaged levees, communications cutoffs, natural dams, and agricultural losses [7]. Typhoon Morakot brought 5 days of rainfall (6-10 August) to southern Taiwan. Rainfall intensity of $20-30 \mathrm{~mm} / \mathrm{hr}$ was prolonged for 48 hours, with intensities over $50 \mathrm{~mm} / \mathrm{hr}$ that lasted up to 24 hours. The maximum rainfall intensity reached $90-100 \mathrm{~mm} / \mathrm{hr}$ in many rain gauge stations. The long rainfall duration caused a cumulative rainfall reaching 2,000 $\mathrm{mm}$ in the plains areas and 3,000 $\mathrm{mm}$ in the mountainous areas of southern Taiwan [4]. The intense, prolonged rainfall occurred because Morakot was a slow moving typhoon [8].

The highest rainfall recorded was 3,060 $\mathrm{mm}$ at the Alishan station in Chiayi County in southern Taiwan [6]. In the study area of Chiayi County, this abnormally heavy rainfall led to 10 deaths with a further two missing, electricity outages for 11,300 buildings, hydraulic structures damaged in 30 places, roads damaged in 25 places, and 206 villages inundated by floods, landslides, and debris flows in over 700 locations, 22 bridges collapsed and 4 damaged, and estimated agricultural losses reaching NT\$ 26 billion [9]. A rainfall threshold that combines the intensity, duration, and cumulative rainfall is commonly used for landslide and debris flow warnings [10]-[15]. At present this rainfall threshold warning model only addresses a single type of hazard (landslides, debris flows, or flood) and is less concerned about the hazards for relief workers and for potential disaster preparedness.

The characteristics of many natural hazards show a 
power-law distribution [16]-[18]. For example, the relationship between the size and frequency of landslides follows a power law distribution [19]-[23].

This study investigates the cumulative number of reported hazards and rainfall during Typhoon Morakot using a power-law distribution analysis. The purpose of the study is promotion of an early warning system for disasters by monitoring of real time rainfall.

\section{Study AREA AND MEthodology}

The study area, Chiayi County, is located in south-central Taiwan (Fig. 2). The elevation of the mountainous areas reaches $3,800 \mathrm{~m}$. The geology consists largely of sandstone and shale layers, with portions of traversing layers of sandstone, mudstone, and shale, and layers of shale, sandy shale, and mudstone in the mountainous area (Central Geology Survey in Taiwan, http://www.moeacgs.gov.tw). The annual rainfall in Taiwan is $2,151 \mathrm{~mm}$ in the center, $2,523 \mathrm{~mm}$ in the south, and 2,926 $\mathrm{mm}$ in the north, with 2,500 $\mathrm{mm}$ being the average for Taiwan between 1949 and 2010 [24]. This study focuses on six mountain villages, including Jhongpu, Dapu, Chuchi, Fanlu, Meishan, and Alishan villages.

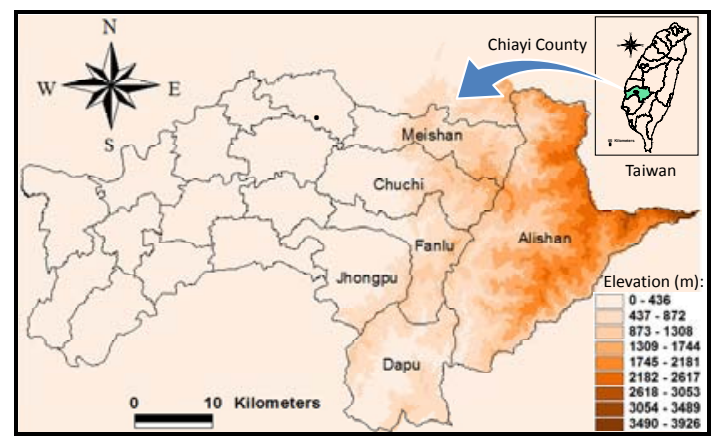

Fig. 2. Site location and elevation of Chiayi County in south-central Taiwan.

This study analyzes the relationships between cumulative hazards and rainfall for the period of 6-28 August, 2009, during and after Typhoon Morakot, in the mountainous areas of Chiayi County. The database includes site location, time of initiation, and the types of hazards. The relationships between hazards and the corresponding rainfall were analyzed using GIS for spatial data analysis.

\section{StATISTICS ANALYSIS OF HAZARDS INDUCED BY TYPHOON MORAKOT}

The reported hazards to the EOC (Emergency Operation Center, EOC) in Chiayi County during Typhoon Morakot totaled 1,695 events during the period 6-28 August. There were 1,182 reported events during the emergency response stage of 6-14 August, and 513 during the recovery stage of 15-28 August, 2009. The number of hazards increased dramatically on 8 to 9 August (Fig. 3). The highest number of hazards, 342 events, occurred on 9 August, with 190 on 10 August during the emergency response stage. The hazards during the recovery stage mainly occurred from 15-17 August, during which 303 hazards occurred in the coastal villages and 182 in the plains. Most of the hazards occurred in the mountainous areas, with 303 cases (66\%). An additional 92 cases lacked identified locations.

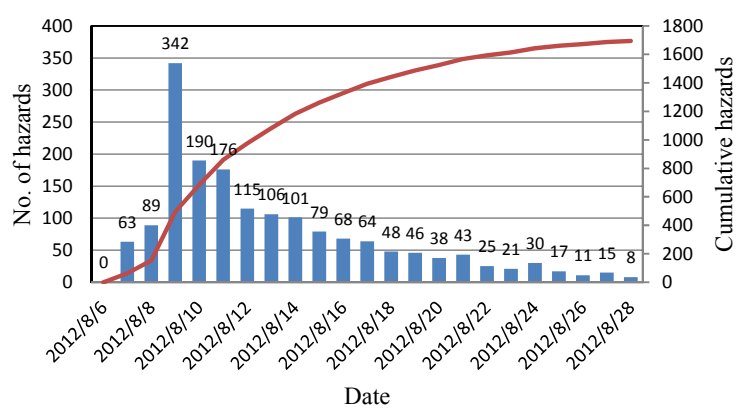

Fig. 3. Daily hazard distribution during and after Typhoon Morakot, 6-28 August 2009 (source: Chiayi County EOC, http://www.cyhg.gov.tw).

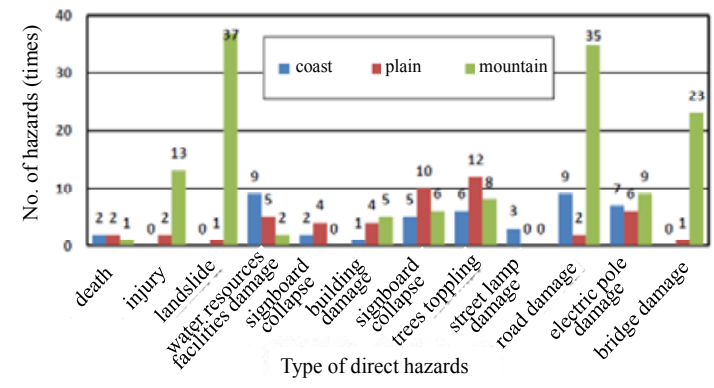

Fig. 4. Number of direct hazards, 6-28 August, 2009, during and after Typhoon Morakot in Chiayi County.

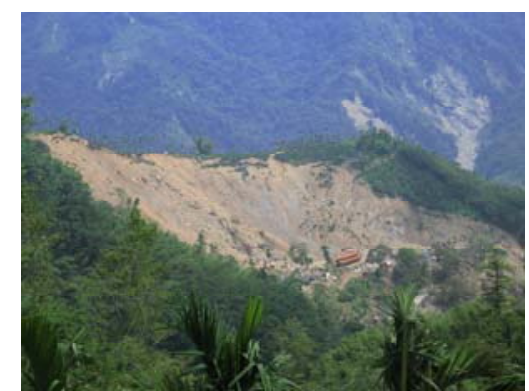

Fig. 5. One of the large landslides in Meishan Township, Chiayi County.

Two categories of hazard, direct and indirect hazards, were identified for the analysis. The direct hazards consist of hazards directly attributable to the typhoon-induced rainfall, including death, injury, road and bridge damage, and landslides and debris flows. Indirect hazards are those not identified as well as secondary hazards such as individuals missing or trapped, building inundation, ponding areas, and power and water outages.

This study identified 241 direct hazards and 1,459 indirect hazards totaling 1,695 events. There were more cases of road damage (46 cases), landslides (38 cases), and bridge damage (24 cases) in direct hazards (Fig. 4). Fig. 5 shows one of the large landslides in the study area. Most of the indirect hazards consisted of people being trapped (313 cases) and ponding (125 cases) in addition to other un-categorized hazards (888 cases) (Fig. 6). Direct hazards such as water resources facilities damage ( 9 cases) and road damage ( 9 cases), along with indirect hazards such as ponding (83 cases) were common in the coastal areas. Direct hazards such as signboard collapse (10 cases) and trees along highways toppling (12 cases), along with the indirect hazard of ponding (31 cases) were highest in plain areas. In mountainous areas, landslides (37 cases) and road damage ( 35 cases) accounted for most of the direct hazards, while residents isolated by 
road cutoff ( 275 cases) were the common indirect hazard.

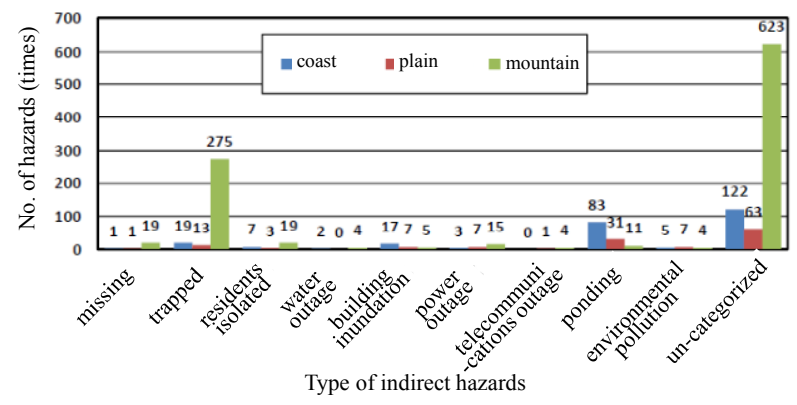

Fig. 6. Number of indirect hazards, 6-28 August, 2009, during and after Typhoon Morakot in Chiayi County.

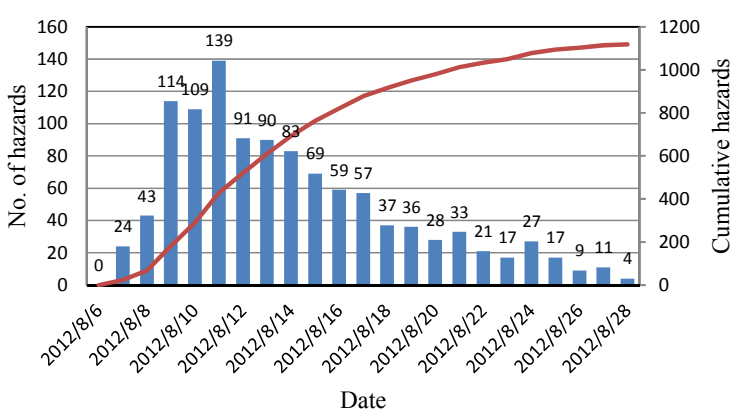

Fig. 7. Number of daily hazards, 6-28 August, 2009, in the mountainous areas of Chiayi County during and after Morakot.

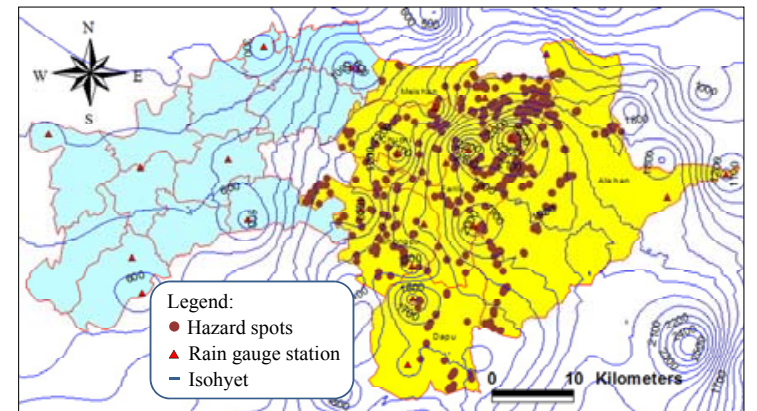

Fig. 8. Isohyet of cumulative rainfall 7-10 August, (source: [6]) and locations of hazards (source: Chiayi county Fire Bureau, 2009) in the mountainous areas of Chiayi County during Typhoon Morakot.

The daily hazard distribution in the mountainous areas of Chiayi County is shown in Fig. 7. The hazards began on the $7^{\text {th }}$ and increased on the $8^{\text {th }}$ through $11^{\text {th }}$ of August during Morakot. The greatest number of daily hazards, 139 cases, occurred on the $11^{\text {th }}$, followed by the $9^{\text {th }}$ (114 cases), and the $10^{\text {th }}$ (109 cases). Hazards increased abruptly from the $8^{\text {th }}$ to $9^{\text {th }}$. Follow on or secondary hazards occurred after the $10^{\text {th }}$ in the post hazard recovery stage.

\section{RAINFALl DistribUTIONS AND HAZARDS}

Fig. 8 shows the locations of hazards during Typhoon Morakot in the mountainous areas of Chiayi County. Debris flows, landslides, road blockages, and broken bridges isolated residents in the mountains. The rainfall data were retrieved from the nearest rain gauge stations (14 stations) in the mountain areas. The rainfall was concentrated from the $6^{\text {th }}$ to the $10^{\text {th }}$ and affected mountain areas from 17:00 on the $7^{\text {th }}$ to $5: 00$ on the $10^{\text {th }}$.

Fig. 9 shows the time history of rainfall distribution for the number of hazards and cumulative rainfall at the Alishan rain gauge station during 7-10 August 2009. The time of day hazards occurred was 6-7 (9 cases), 9-10 (9 cases), and 10-11 (12 cases) in 9 August. In general, the number of hazards increased with the cumulative rainfall during the period the typhoon affected the study area (17:00 on the 7 until 5:00 on the 10 of August).

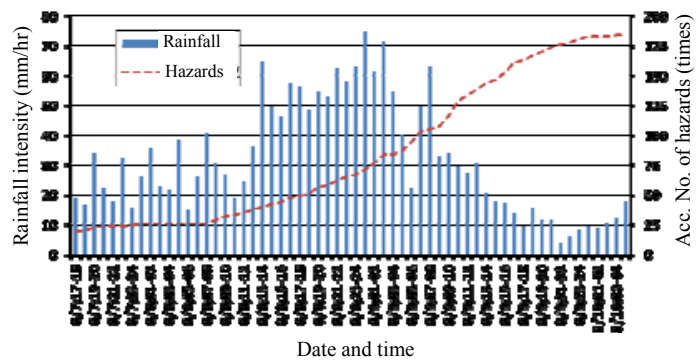

Fig. 9. Rainfall intensity at the Alishan rain gauge station and cumulative hazards, 7-10 August, 2009.

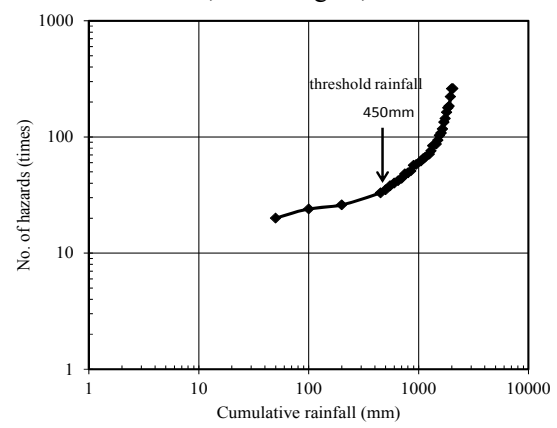

Fig. 10. Cumulative hazards and rainfall (Alishan rain gauge station) in the mountainous areas of Chiayi County, 7-10 August 2009.
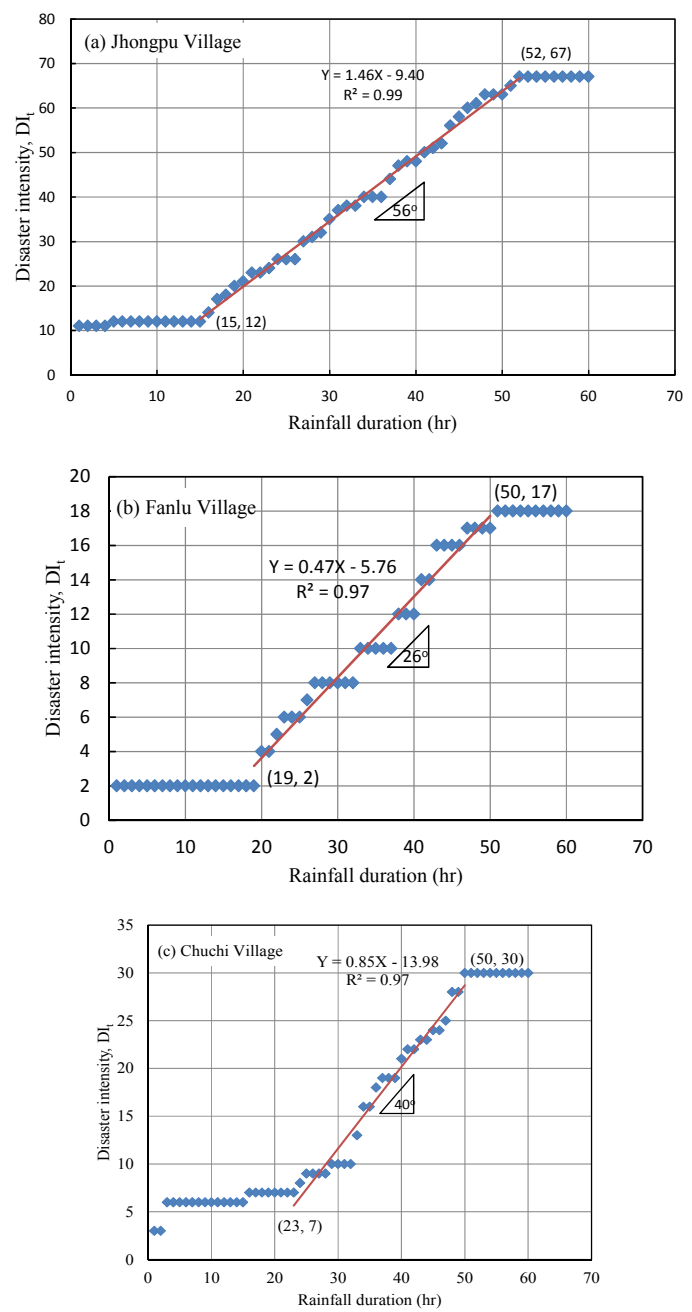

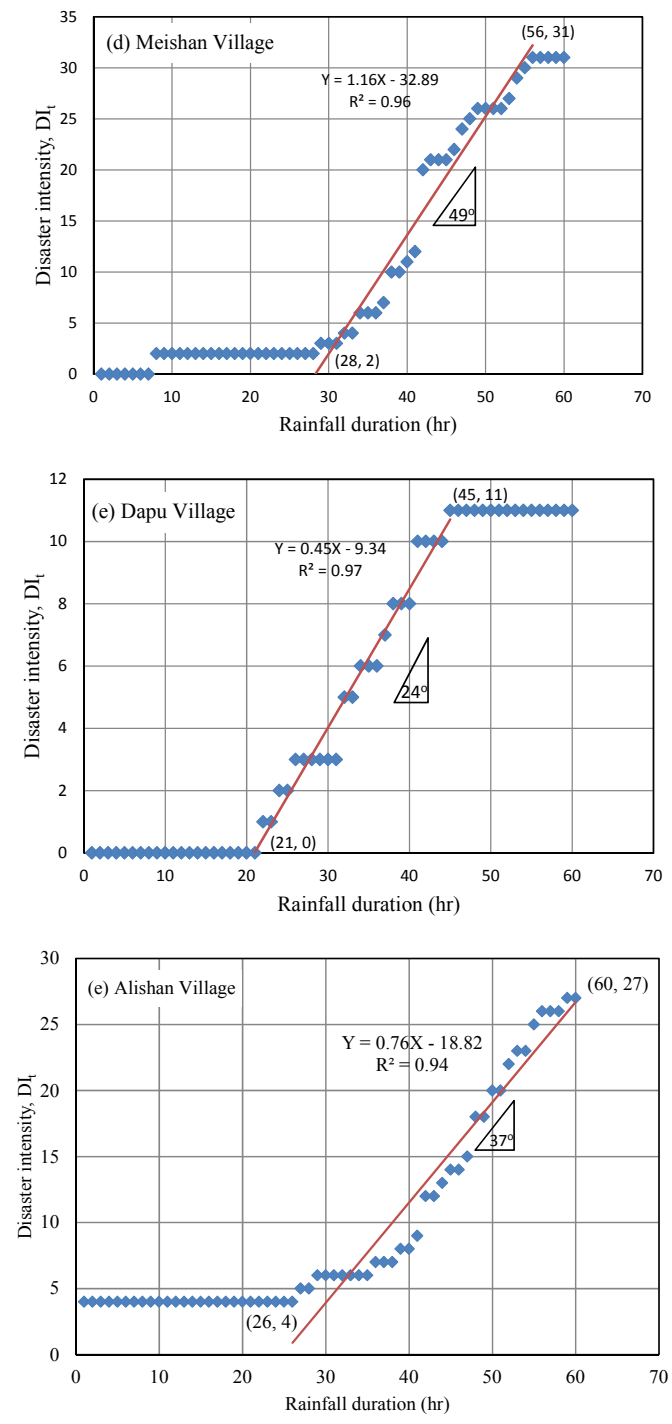

Fig. 11. Disaster intensity $\left(\mathrm{DI}_{\mathrm{t}}\right)$ and rainfall duration at the nearest rain gauge station during Typhoon Morakot in Chiayi County in (a) Jhongpu (b) Fanlu (c) Chuchi (d) Meishan (e) Dapu and (f) Alishan villages.

\section{RESULTS AND DISCUSSION}

This study plots the distribution of the cumulative rainfall and the number of hazards (Fig. 10). The number of hazards rose with every $50 \mathrm{~mm}$ of increased rainfall. Most of the villages have a high threshold rainfall corresponding to an abrupt increase in hazards in the plot. The threshold rainfall, at which level there is an abrupt increase in hazards, is estimated $450 \mathrm{~mm}$ over the study area as a whole. As the gradient of rainfall increases, the number of hazards also increases.

To address this issue of unclear cumulative rainfall thresholds and the number of hazards for early warning of hazards, a novel index is proposed herein. The number of hazards was calculated for every one hour of rainfall duration (dT). This time interval, one hour, was chosen for the accessibility of rainfall data. For instance, rainfall data per ten minutes is available in Taiwan. The Disaster Intensity $\left(D_{t}\right)$ is defined as the cumulative number of hazards $\left(N_{c}\right)$ with increasing rainfall duration in a specified interval (one hour).

$$
D I_{t}=f(T)=d N_{c} / d T
$$

The relationships between the hazard intensity and rainfall duration show a power-law distribution in the main rainfall period during Typhoon Morakot in the study area (Fig. 11). The data show a parallel distribution if no new hazards occurred within the time interval $(d T)$. The relationship between $D I_{t}$ and rainfall duration $(T)$ in the mountains area and the Alishan rain gauge station is presented in Fig. 12 and its regression equation listed below.

$$
D I_{t}=4.24 T^{52.8}\left(r^{2}=0.98\right)
$$

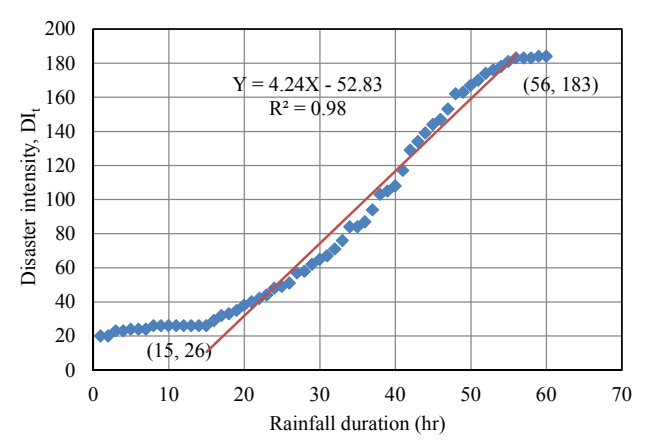

Fig. 12. Disaster Intensity $\left(D I_{t}\right)$ and rainfall duration at the Alishan rain gauge station in the mountainous areas of Chiayi County.

The sharp increases in hazards began after 15 hours of rainfall duration and a corresponding cumulative rainfall of $372 \mathrm{~mm}$. The model show its validation from a small area of township to the whole studied wide mountainous area with a scale invariant feature. The gradient of the regression line shows the increasing of hazards with the rainfall duration. The steeper of the gradient, the higher vulnerability of the area to hazards. Jongpu Village shows its high vulnerability to hazards and Dapu Village shows less feasible to hazards among the study villages.

TABLE I: COMPARISONS OF RAINFALL THRESHOLD FOR HAZARDS BY THIS STUDY AND BY THE SWCB FOR DEBRIS FLOW WARNING

\begin{tabular}{llll}
\hline \hline Village & $\begin{array}{l}\text { Threshold } \\
\text { rainfall }(\mathrm{mm})\end{array}$ & $\begin{array}{l}\text { Threshold } \\
\text { duration }(\mathrm{hr})\end{array}$ & $\begin{array}{l}\text { Threshold } \\
\text { rainfall* }(\mathrm{mm})\end{array}$ \\
\hline Jhongpu & 200 & 15 & 400 \\
Fanlu & 500 & 19 & 450 \\
Chuchi & 750 & 23 & 350 \\
Meishan & 600 & 28 & 300 \\
Dapu & 750 & 21 & 400 \\
Alishan & 900 & 26 & 250 \\
Mountainous & 450 & 15 & - \\
areas & & & \\
\hline \hline
\end{tabular}

*Published by SWCB (http://www.swcb.gov.tw)

A Rainfall Triggering Index (RTI) was proposed by real time rainfall monitoring for debris flow early warning in Taiwan [25]. The threshold rainfall considered the effective accumulated rainfall and antecedent rainfall published by the SWCB for villages with debris flow potential areas. This study compared the proposed threshold rainfall and the published threshold for debris flows (Table I). It is found that the published rainfall threshold for debris flows was lower than this study's proposed threshold rainfall in most of the villages. The minimum rainfall duration for hazards increasing abruptly is $15 \mathrm{hrs}$. In addition to Jhongpu village, the published threshold rainfall is higher than herein, which 
could lead to failure to provide early warning of potential hazard occurrences for residents.

\section{CONCLUSION}

The study explores the relationships between hazards, rainfall amount, and duration of rainfall during Typhoon Morakot in 2009 in Chiayi County, Taiwan. The hazards mainly occurred in mountainous areas on 9-10 August, 2009. Most of the hazards were located in areas of high cumulative rainfall, between 1,500 and $2,000 \mathrm{~mm}$. The number of hazards increased with increases in cumulative rainfall. The cumulative number of hazards and rainfall duration displays a power-law distribution over a threshold rainfall (450 $\mathrm{mm}$ in mountainous areas). The threshold rainfall can be used for hazard early warning and evacuation. This study thus provides a novel approach to rainfall-induced hazard warning for homeland security.

\section{ACKNOWLEDGMENT}

Financial supports from the National Science Council of Taiwan under contract no. NSC 102-2221-E-415-008-MY3 is appreciated.

\section{REFERE NCES}

[1] E. Kerry, R. Sundararajan, and J. Williams, "Hurricanes and global warming: Results from downscaling IPCC AR4 simulations," Bulletin of the American Meteorological Society, vol. 89, pp. 347-367, March 2008.

[2] M. Beniston, M. Stoffel, and M. Hill, "Impacts of climatic change on water and natural hazards in the Alps: Can current water governance cope with future challenges? examples from the European 'ACQWA' project," Environmental Science and Policy, vol. 14, pp. 734-743, November 2011.

[3] S. Russell, L. Limalevu, G. Singh, and R. Pathak, "Building resiliency to natural hazards in Pacific island communities," The International Journal of Climate Change: Impacts and Responses, vol. 3, no. 3, pp. $11-30,2012$

[4] NCDR, "National Science and Technology Center for Disaster Reduction," Typhoon Morakot Induced Disasters Investigation and Analysis, pp. 5-18, 2010.

[5] Morakot Post-Disaster Reconstruction Council. (2010). [Online]. Available: http://88flood.www.gov.tw/.

[6] CWB, Central Weather Bureau in Taiwan. (2009). [Online]. Available: http://www.cwb.gov.tw/V7/index.htm.

[7] CEOC, Central Emergency Operation Center, National Fire Agency, Ministry of the Interior. [Online]. Available: http://www.nfa.gov.tw.

[8] J. D. B. Jou, Y. C. Yu, L. Feng, Y. M. Chen, C. S. Lee, and M. D. Cheng, "Synoptic environment and rainfall characteristics of Typhoon Morakot," Atmospheric Science, vol. 38, no. 1, pp. 21-38, June 2010.

[9] Chiayi County Government. (2009). [Online]. Available: http://www.cyhg.gov.tw.

[10] P. Aleotti, "A warning system for rainfall-induced shallow failures," Engineering Geology, vol. 73, pp. 247-265, June 2004.

[11] S. H. Cannon and S. D. Ellen, "Rainfall conditions for abundant debris avalanches, San Francisco Bay region," California Geology, vol. 38, no. 12 , pp. 267-272, 1985.

[12] C. Y. Chen, T. C. Chen, F. C. Yu, W. H. Yu, and C. C. Tseng, "Rainfall duration and debris-flow initiated studies for real-time monitoring," Environmental Geology, vol. 47, no. 5, pp. 715-724, March 2005.
[13] J. Cepeda, K. Höeg, and F. Nadim, "Landslide-triggering rainfall thresholds: a conceptual framework," Quarterly Journal of Engineering Geology and Hydrogeology, vol. 43, pp. 69-84, February 2010.

[14] F. Guzzetti, S. Peruccacci, M. Rossi, and C. P. Stark, "Rainfall thresholds for the initiation of landslides in central and southern Europe," Meteorology and Atmospheric Physics, vol. 98, pp. 239-267, December 2007.

[15] R. Giannecchini, Y. Galanti, and G. D’Amato Avanzi, "Critical rainfall thresholds for triggering shallow landslides in the Serchio River Valley (Tuscany, Italy)," Natural Hazards and Earth System Science, vol. 12, pp. 829-842, March 2012.

[16] P. Bak, How Nature Works. The Science of Self-organized Criticality, Copernicus, An Imprint of Springer-Verlag, New York Inc., New York, $1997,212 \mathrm{pp}$.

[17] D. L. Turcotte, B. D. Malamud, F. Guzzetti, and P. Reichenbach, "Self-organization, the cascade model, and natural hazards," in Proc. the National Academy of Sciences of the United States of America, vol. 99, no. 3, pp. 2530-2537, February 2002.

[18] S. Hergarten, "Aspects of risk assessment in power-law distributed natural hazards," Natural Hazards and Earth System Science, vol. 4, no. 2, pp. 309-313, April 2004

[19] C. P. Stark and N. Hovius, "The characterization of landslide size distributions," Geophysical Research Letters, vol. 28, pp. 1091-1094, December 2001.

[20] F. Guzzetti, B. D. Malamud, D. L. Turcotte, and P. Reichenbach, "Power-law correlations of landslide areas in central Italy," Earth and Planetary Science Letters, vol. 195, pp. 169-183, February 2002.

[21] M. V. D. Eeckhaut, J. Poesena, G. Goversa, G. Verstraetena, and A. Demoulin, "Characteristics of the size distribution of recent and historical landslides in a populated hilly region," Earth Surface Processes and Landform, vol. 256, pp. 588-603, April 2007.

[22] C. Y. Chen, F. C. Yu, S. C. Lin, and K. W. Cheung, "Discussion of landslide self-organized criticality and the initiation of debris flow," Earth Surface Processes and Landform, vol. 32, pp. 197-209, February 2007.

[23] C. Y. Chen, "Landslide and self-organized criticality in the Lushan hot spring area," Journal of Mountain Science, vol. 9, no. 4, pp. 463-471, August 2012.

[24] WRA: Water Resources Agency. Ministry of Economic Affairs in Taiwan. [Online]. Available: http://gweb.wra.gov.tw/ebooks/ebook/

[25] C. D. Jan and M. S. Lee, "A debris-flow rainfall-based warning model," Journal of Chinese Soil and Water Conservation, vol. 35, no. 3, pp. 275-285, September 2004.

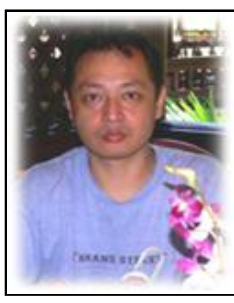

Chien-Yuan Chen was born on Oct. 27, 1969, in Changhua City, Taiwan. He received his Ph.D. in civil and environmental engineering form University of Southern California, Los Angeles, USA, in 2001 $\mathrm{He}$ received his M.Sc. in civil engineering from National Cheng Kung University, Taiwan, in 1995.

He was an associate research fellow (2001-2006) at Slopeland Disaster Reduction Division, National Science and Technology Center for Disaster Reduction (NCDR), Sindian District, and New Taipei City, Taiwan. He was an assistant professor and an associate professor at Department of Civil and Water Resources Engineering, National Chiayi University. He is currently as a professoat Department of Civil and Water Resources Engineering, National Chiayi University, Chiayi City, Taiwan. His research is focused on the following: disaster prevention management and system, disaster prevention education, debris flow and landslide hazards prevention and mitigation, Geotechincal engineering, GIS application and numerical modeling.

He is a member of Disaster Management Society of Taiwan. He's previous publications included:

C. Y. Chen, F. C. Yu, S. C. Lin, and K. W. Cheung, "Discussion of landslide self-organized criticality and the initiation of debris flow," Earth Surface Processes and Landform, vol. 32, i2, pp. 197-209, 2007, ect. 